\title{
Study of Nanomaterials Prepared by Combustion Method Using High Heat Combustion Chamber and Agreement with the Reported Results
}

\section{Perumalsamy $\mathbf{R}^{1,2}$, Prabhavathi $\mathbf{G}^{1,3}$, Nivetha $\mathbf{S}^{1,3}$, Mohamed Saleem $\mathbf{A}^{1,4}$, Karunanithy $\mathbf{M}^{1,5}$, Ayeshamariam $\mathbf{A}^{1,3 *}$ and Jayachandran $\mathbf{M}^{6}$}

${ }^{1}$ Research and Development Center, Bharathidasan University, Thiruchirappalli, 620024, India

${ }^{2}$ Department of Physics, Thiagaraya College Higher Secondary School, Chennai, 600021 India

${ }^{3}$ Department of Physics, Khadir Mohideen College, Adirampattinam, 614701, India

${ }^{4}$ Department of Physics, Jamal Mohamed College, Thiruchirappalli, 620020, India

${ }^{5}$ Department of Physics, SKPD Boys Higher Secondary School, Chennai, 600001, India

${ }^{6}$ Department of Physics, Sethu Institute of Technology, Pullor, Kariyapatti, 626115, India

\begin{abstract}
Nanocrystalline materials such as $\mathrm{Sn}$ doped $\mathrm{In}_{2} \mathrm{O}_{3}$ Indium Tin Oxide (ITO) were prepared by this Combustion technique and characterized. Presence of electronic centers in Nanocrystalline ITO is observed from Raman studies and the same has been confirmed by photoluminescence studies. The oxidation properties of ITO were studied by X-ray Diffract meter grain sizes are confirmed by structural studies. As against the expectation of oxide on individual Nano grains of In-Sn alloy, ITO Nano grains grew into faceted Nano grains on heat treatment in air and $\mathrm{O}_{2}$ atmosphere. The growth of ITO under $\mathrm{O}_{2}$ atmosphere showed pentagon symmetry. This Nanocrystalline ITO has been studied using Electron paramagnetic resonance (EPR) measurements. Structural studies by X-Ray Diffraction (XRD) showed the presence of dominant $\beta$ phase with a minor quantity of $\alpha$ phase. In EPR, isotopic chemical shift peaks were observed and they are assigned to originate from the $\alpha, \beta$ phases of ITO and grain boundary component respectively. From this study, different atomic arrangements were identified in grain boundaries compared to the same within the grain in Nanocrystalline ITO. The atomic arrangement in the grain boundary seems to be somewhat different from regular periodic arrangement whereas inside the grain there is a good periodic arrangement of atoms. Above $5 \mathrm{~mol} \%, \mathrm{Sn}$ ions form correlated clusters, which lead to broadening. These EPR spectra were formed to contain two different components, one from the single isolated ions and the other from the clusters.
\end{abstract}

Keywords: Electron paramagnetic resonance (EPR); X-ray diffraction (XRD); Nanocrystalline indium tin oxide (ITO), Combustion

\section{Introduction}

The recent field of nanoscience and nanotechnology has attracted much interest in research as they fixed many applications [1]. All ITO materials are technologically very important for gas sensors. ITO is used as a transparent and conducting electrode in solar cells. In this study, preparation and characterization of nanoform of these materials and their important features will be discussed. These materials exhibit physical and chemical properties, which are partially or totally different from their coarse grained materials. Technique such as XRD [2], and Electron paramagnetic resonance (EPR) etc. have assisted the growth of this field. Even though many materials have been prepared by furnace, in the present work, we report the results of some of the nanocrystalline materials such as $\mathrm{In}_{2} \mathrm{O}_{3}$ doped with $\mathrm{SnO}_{2}$. ITO particles have been analysed by several researchers and a reasonable understanding has been arrived in transport and optical properties [3].

Metal oxide-based sensors, such as tin oxide, indium oxide and indium tin oxide (ITO), are often mixed with many different metallic to enhance both their sensitivity and selectivity. Gas sensors based on semi conducting oxides present some advantages with respect to other types of gas sensors.

While several synthesis and processing methods have been employed for making thin-films of ITO research on nano-particles, chemical methods is the best technique to synthesize ITO powdered nano-particles. Solution combustion method has emerged as the important technique for the synthesis and processing of advanced ceramics catalysts, composites, alloys, intermetallic and nanomaterials. Today Solution combustion method is being used all over the world to prepare oxide materials for a variety of applications. It was possible to prepare oxide material with desired composition. Solution combustion has been directed towards a better understanding of the role of the fuel urea in controlling the particle size and microstructure of the combustion products.

\section{Experimental Section}

Calculated amount of $\operatorname{In}\left(\mathrm{NO}_{3}\right)_{3}(5.0 \mathrm{M})$, dissolved in minimum volume of water was added to the aqueous $(5.0 \mathrm{M})$ to $(0.5 \mathrm{M})$ solution of $\mathrm{Sn}\left(\mathrm{NO}_{3}\right)_{2}$ obtained by stirring the In-metal ingots with concentrated $\mathrm{HNO}_{3}$ for $40 \mathrm{~h}$ at $100^{\circ} \mathrm{C}$. The volume of $\operatorname{In}\left(\mathrm{NO}_{3}\right)_{3}$ solution and the weight of $\mathrm{Sn}\left(\mathrm{NO}_{3}\right)_{2}$ were taken by maintaining the $\mathrm{In} / \mathrm{Sn}$ atomic ratio 50:50, 75:25, 85:15, 80:20, 90:10 and 95:05. The mixture was diluted with water and the resultant solution was stirred magnetically for $2 \mathrm{~h}$. Urea was added to the above mixture till a gel of hydrated indium tin oxide appeared. It was stirred for additional $1 \mathrm{~h}$ at an ambient temperature. The $\mathrm{pH}$ of the above solution was maintained in the range 8.5-8.8 at this stage. The solution was stirred again for $1 / 2 \mathrm{~h}$ to ensure the complete precipitation. The precipitation was placed in a hot plate at $100^{\circ} \mathrm{C}$ for 20 min until it turned as gel.

The mixed salt solutions of different molar ratios in water were

*Corresponding author: Ayeshamariam A, Research and Development Center, Bharathiyar University, Coimbatore, 641046, India, Tel: +91 4565-241539; E-mail: aismma786@gmail.com

Received August 20, 2017; Accepted September 10, 2017; Published September 20, 2017

Citation: Perumalsamy R, Prabhavathi G, Nivetha S, Mohamed Saleem A, Karunanithy M, et al. (2017) Study of Nanomaterials Prepared by Combustion Method Using High Heat Combustion Chamber and Agreement with the Reported Results. Fluid Mech Open Acc 4: 175. doi: 10.4172/2476-2296.1000175

Copyright: (c) 2017 Perumalsamy R, et al. This is an open-access article distributed under the terms of the Creative Commons Attribution License, which permits unrestricted use, distribution, and reproduction in any medium, provided the original author and source are credited. 
Citation: Perumalsamy R, Prabhavathi G, Nivetha S, Mohamed Saleem A, Karunanithy M, et al. (2017) Study of Nanomaterials Prepared by Combustion Method Using High Heat Combustion Chamber and Agreement with the Reported Results. Fluid Mech Open Acc 4: 175. doi: 10.4172/2476-2296.1000175

Page 2 of 8

treated with different urea compound $\mathrm{pH}$ 8.5-8.7 to obtain hydrated In(III) and Sn(IV) hydroxides. The transformation of co-precipitated hydrated In(III) and Sn(IV) hydroxides to oxides of In(III) and Sn(IV) requires thermal curing. Hence, thermo gravimetric analyses of the samples were performed up to maximum temperature $1200^{\circ} \mathrm{C}$ for the analysis of the systematic weight loss of the hydrated hydroxides. The pure hydrated hydroxide of In(III)/Sn(IV) was also precipitated in the same manner from the above mentioned starting materials and analyzed thermogravimetrically for comparing its decomposition pattern with that of the mixed systems.

The weight loss of the air-dried samples (pure and mixed systems) with temperature (between ambient temperature and $1200^{\circ} \mathrm{C}$ ) showed interesting results up to $700^{\circ} \mathrm{C}$. Results of the thermal analysis are show in Figure 1. The different thermal analysis (DTA) of pure indium hydroxide system showed a broad endothermic peak between 105 and $202^{\circ} \mathrm{C}$ consisting of three overlapping peaks at 140,175 and $210^{\circ} \mathrm{C}$ and a sharp peak at $203^{\circ} \mathrm{C}$, while in the case of pure tin system, only an endothermic peak centered at $\sim 156^{\circ} \mathrm{C}$ was observed between ambient temperature and $300^{\circ} \mathrm{C}$. As the indium system exhibits a number of overlapping endotherms it would transform to $\operatorname{In}_{2} \mathrm{O}_{3}$ through a number of meta stable states. From the weight loss, empirical formations for the intermediates may be predicated and their possible structural formations have also been elucidated (Figure 1) as evident form the FTIR spectra (see below) of the moieties arrested at specific temperatures where two overlapping peaks intersects which is supposed to be the meta stable state position. On the other hand, the Sn system transformed to oxide of Sn via only one step. The empirical formula and the possible structure based on thermal analysis are depicted in Figure 1. comparing the FTIR spectra (discussed below) of the samples arrested at different temperatures as per the TG and DTA analysis, it may be predicted that the indium (III) hydroxide (in case of pure system) was precipitated as $\operatorname{In}(\mathrm{OH})_{3} \cdot \mathrm{H}_{2} \mathrm{O}$ and it decomposed to $\operatorname{In}(\mathrm{OH})_{3}$ after $100^{\circ} \mathrm{C}$, which further transformed to $\operatorname{In}_{2} \mathrm{O}_{3}$ at higher temperature $\left(\right.$ after $264^{\circ} \mathrm{C}$ ) via a number of plausible paths (Figure 1).

DTA of the missed system showed two endothermic peaks centered at $100-212^{\circ} \mathrm{C}$ and $200-400^{\circ} \mathrm{C}$. It is interesting to all cases, but the other endothermic peak observed between 100 and $120^{\circ} \mathrm{C}$ remained unchanged in all cases, but the other endothermic peak observed between 200 and $400^{\circ} \mathrm{C}$ shifted towards the low temperature with increase in Sn content (up to $30 \%$ ), the decomposition pattern prefers the path of Sn system $\operatorname{In}_{2} \mathrm{O}_{3}$, whereas above $30 \%$ of $\mathrm{Sn}$, the decomposition pattern prefers the path of $\mathrm{Sn}$, system $\mathrm{SnO}_{2}$. It is reported that for mixed
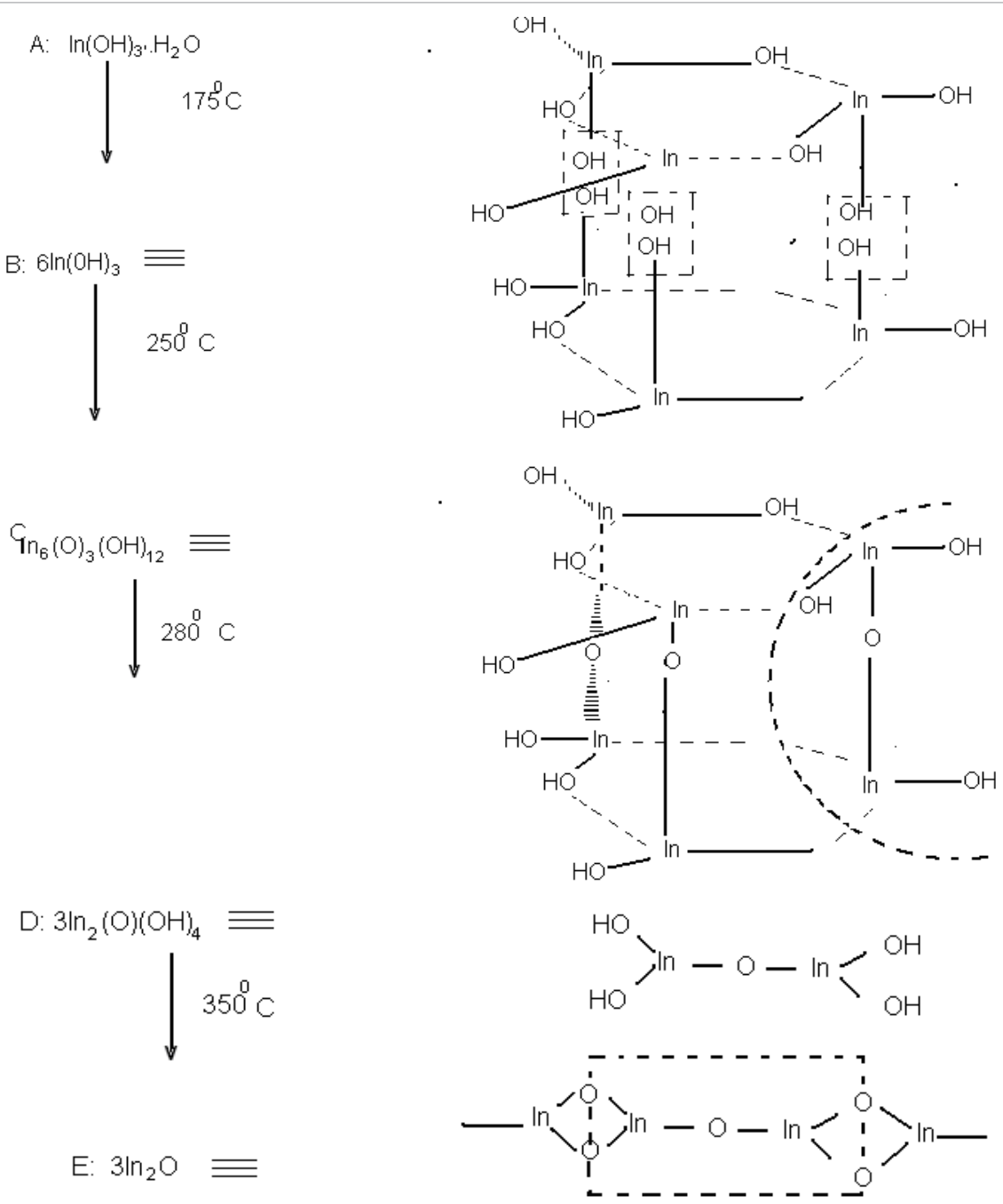

Figure 1a: Proposed empirical formulations during the conversion of pure $\ln (\mathrm{III})$ hydroxide to $\operatorname{In}_{2} \mathrm{O}_{3}$ with temperature. 
Citation: Perumalsamy R, Prabhavathi G, Nivetha S, Mohamed Saleem A, Karunanithy M, et al. (2017) Study of Nanomaterials Prepared by Combustion Method Using High Heat Combustion Chamber and Agreement with the Reported Results. Fluid Mech Open Acc 4: 175. doi: 10.4172/2476-2296.1000175

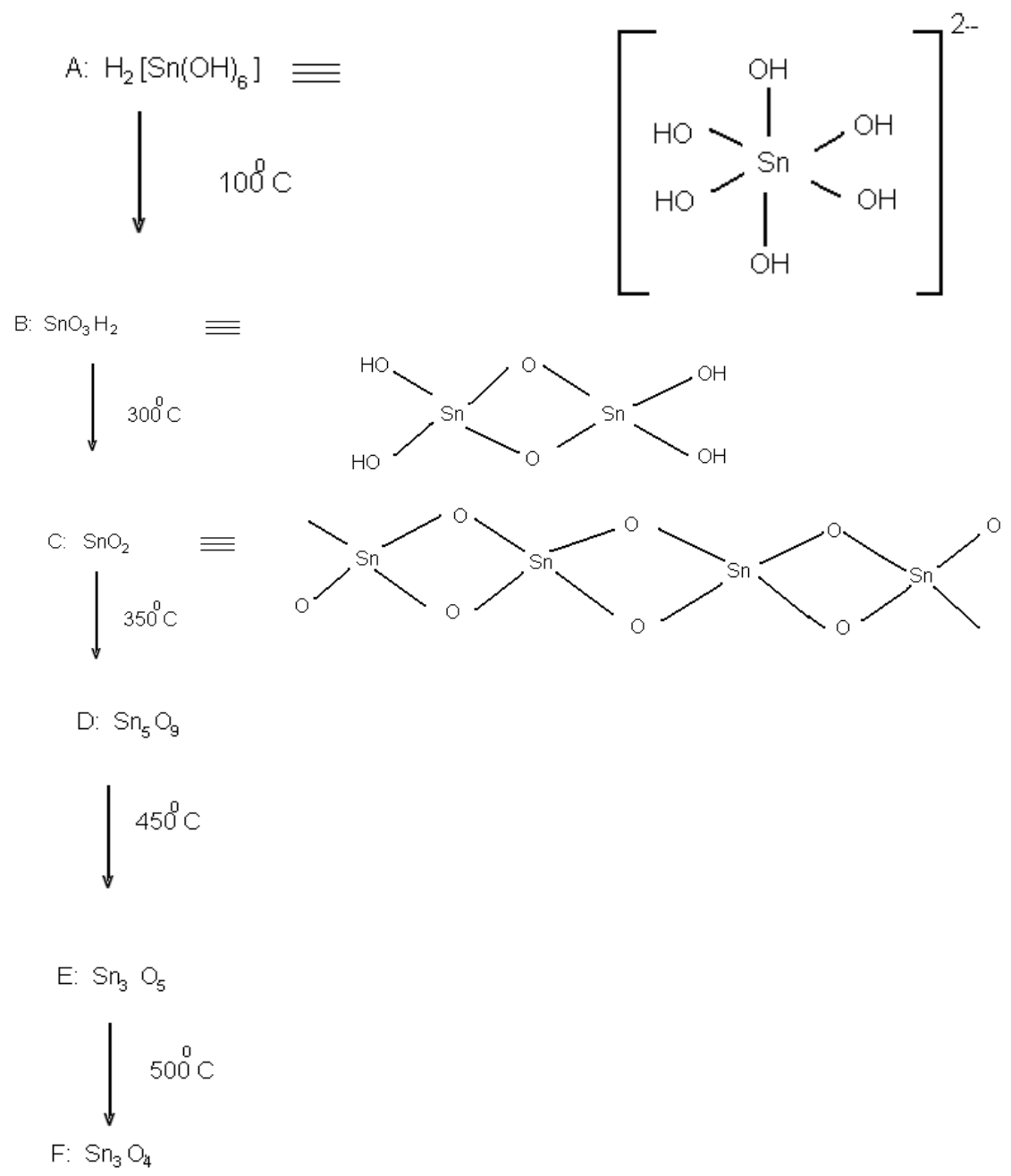

Figure 1b: Proposed empirical formulations during the thermal decompositions of pure Sn (IV) hydroxide with temperature.

systems, $\mathrm{In}(\mathrm{OH})_{3}$ yielded $\operatorname{In}_{2} \mathrm{O}_{3}$ at relatively lower temperature (200 and $225^{\circ} \mathrm{C}$ in the case of $\mathrm{In} / \mathrm{Sn}=50: 50,0.75: 25,85: 15,80: 20$ and $90: 10$ and 95:05, respectively), which was evidenced by only a sharp peak between 255 and $267^{\circ} \mathrm{C}[4]$.

It is reported in literature $[5,6]$ that the $\mathrm{H}_{2}\left[\mathrm{Sn}(\mathrm{OH})_{6}\right]$ underwent thermal decomposition and yielded $\mathrm{SnO}_{3} \mathrm{H}_{2}$ on heating $\sim 100^{\circ} \mathrm{C}$, which ultimately transformed to tetragonal $\mathrm{SnO}_{2}$ phase via the decomposition of remaining $\mathrm{OH}$ groups at relatively high temperature (say $350^{\circ} \mathrm{C}$ ). Pure tin hydroxide system showed three other endothermic peaks at 365,458 and $525^{\circ} \mathrm{C}$, which were also due to some others polymeric tin oxide systems. A possible path of transformation from hydroxide to metal oxide is depicted in Figure 2. Tin(IV) hydroxide in pure Sn system is presumed to have the octahedral $\left[\mathrm{Sn}(\mathrm{OH})_{6}\right]^{2-}$, where the six octahedral positions are occupied by $\mathrm{OH}^{-}$ions which are not existing at higher temperature.

Figure 2 shows the XRD patterns for as prepared under different proportions. XRD studies of the as prepared material show the presence of in lines indicating that Sn has gone to the substitutional position forming solid solution. XRD shows complete oxidation of the alloy giving mainly cubic phase of $\operatorname{In}_{2} \mathrm{O}_{3}$. In the present study the main aim was to get core shell structure of Indium and tin metallic alloy nanopowder. If the desired nanostructure is obtained having different molar ratio with 12 to $20 \mathrm{~nm}$ grain size, electron confinement is expected and one can look for single electron conduction through ITO nanopowder without the formation of a depletion region in the semiconductor region [3].

The forms a solid solution in indium up to $50 \%$ [4] with variation in bond length and lattice parameter. In the present work 5 at\% Sn to 0.5 at $\% \mathrm{Sn}$ has been added and fired in a furnace to get nanocrystalline alloy. It has been studied for its oxidation behavior with various compositions. Figure 3 shows the XRD patterns for as-prepared with seven different compositions. XRD studies of the as-prepared material show the presence of tetragonal In lines indicating that $\mathrm{Sn}$ has gone to the substitutional position forming solid solution. XRD shows complete oxidation of the alloy giving mainly cubic phase of $\operatorname{In}_{2} \mathrm{O}_{3}$. Abel et al. [5] have obtained under (Figure 3), XRD Crystal structure of ITO similar conditions, core-shell structure of InSn metallic alloy with ITO, which is a well-known n-type semiconductor. If the desired core-shell structure is obtained having InSn alloy with 12 to $20 \mathrm{~nm}$ grain size as a core, electron confinement is expected and one can look for single electron conduction through ITO without the formation of a depletion region in the semiconductor region. However, because of crystal structure difference, tetragonal for the alloy and either cubic (or orthorhombic) for the oxide, such a core-shell structure is not formed 
Citation: Perumalsamy R, Prabhavathi G, Nivetha S, Mohamed Saleem A, Karunanithy M, et al. (2017) Study of Nanomaterials Prepared by Combustion Method Using High Heat Combustion Chamber and Agreement with the Reported Results. Fluid Mech Open Acc 4: 175. doi: 10.4172/2476-2296.1000175

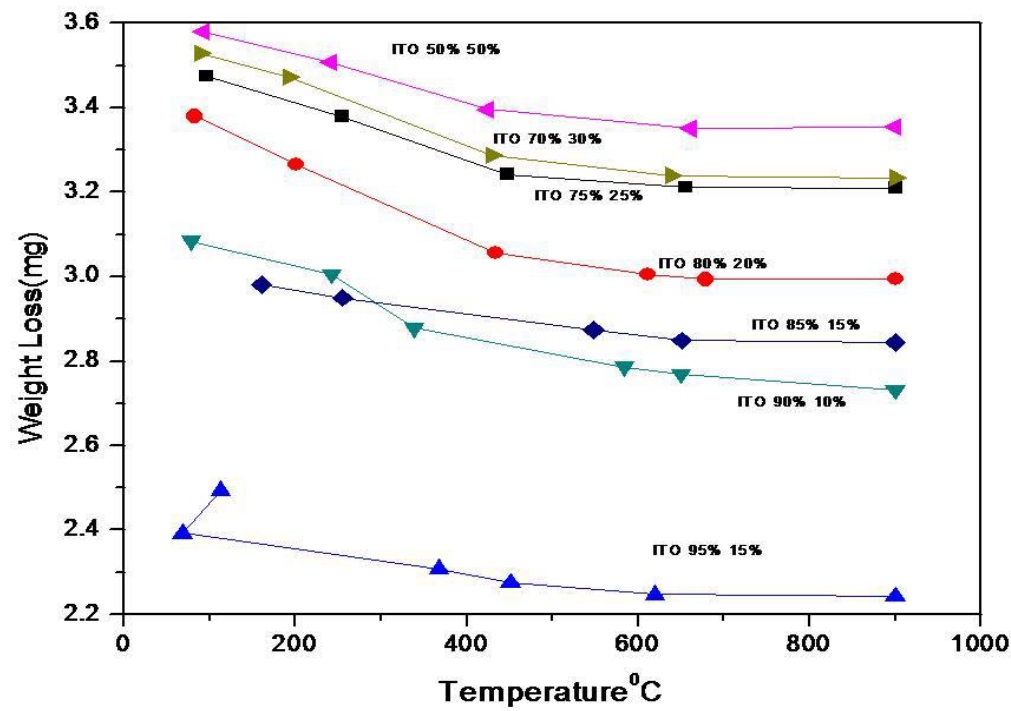

Figure 2: Weight loss from TGA and DSC analysis of ITO (50:50, 70:30, 75:25, 80:20, 85:15, $90: 10$ and 95:05) at different proportions.

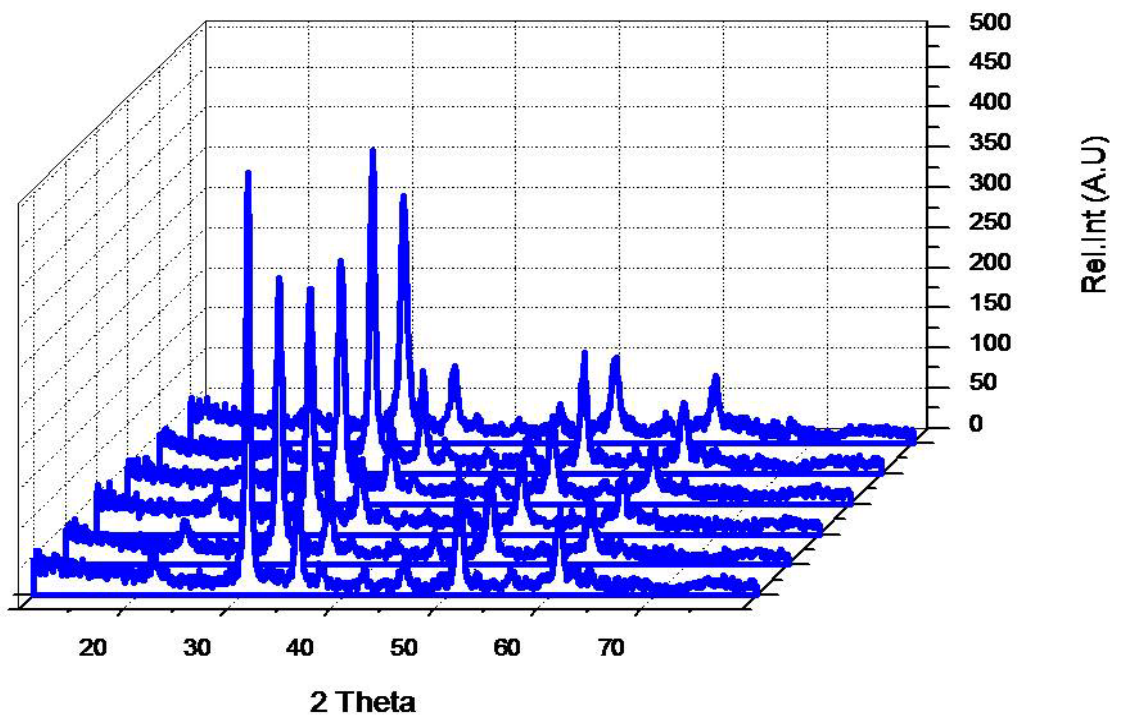

Figure 3: XRD Analysis of different proportions of (50:50, 70:30, 75:25, 80:20, 85:15, $90: 10$ and 95:05) ITO NPs.

in our case. The alloy is partially oxidized with approximately $50 \%$ cubic phase and $50 \%$ orthorhombic phase as can be observed by XRD. We have studied the surface chemistry of ITO and we have found that several metal alkoxides can react with surface hydroxyl / $(\mathrm{OH})$ groups to give well defined surface bound complexes of fixed stoichiometry [6-8].

Figure 4 shows PL emission spectra of conventional particles and nanoparticles of $\mathrm{SnO}_{2}$ prepared at different heat treatments at $250 \mathrm{~nm}$ excitation. Two prominent peaks at 450, 467, 473, 481 and $492 \mathrm{~nm}$ have been observed in the range $420-500 \mathrm{~nm}$. Particularly, the peak position at $460 \mathrm{~nm}$ [5] is sharp and unchanged for all samples, but its intensity tends to reduce with heat treatment temperature. It is due to the characteristics of the traps present in the nanoparticles. This position is chosen for comparison for all samples. Peaks around $400 \mathrm{~nm}$ [6] are very sharp. It is shifted towards the lower wavelength or blue shift with lower dopant of Sn . It is due to structural defects. Usually, defect in lattice decreases with increase of Sn concentration.

Inset (Figure 4) shows the relative peak intensity ratio emission $\sim 400 \mathrm{~nm}$ to $490 \mathrm{~nm}$ in wavelength range $420-500 \mathrm{~nm}$ for different doping of $\mathrm{SnO}_{2}$ of ITO samples. The atomic ratio of sn increases from $5 \mathrm{wt} \%$ to $50 \mathrm{wt} \%$. With the increase of Sn concentration, particle size increases and consequently, surface to volume ratio decreases. Because of this, the intensity of peak at $470 \mathrm{~nm}$ due to surface traps decreases with increase of particle size $[9,10]$. In addition, the non-radiative transition probability decreases with lower dopant to higher dopant of Sn concentration. It results in increase of intensity of the band-band transition at $\sim 400 \mathrm{~nm}$ with increasing $\mathrm{Sn}$ concentration. If this happen, only a few portions are transmitted radiatively and most of the excited energy is lost non-radioactively. 
Citation: Perumalsamy R, Prabhavathi G, Nivetha S, Mohamed Saleem A, Karunanithy M, et al. (2017) Study of Nanomaterials Prepared by Combustion Method Using High Heat Combustion Chamber and Agreement with the Reported Results. Fluid Mech Open Acc 4: 175. doi: $10.4172 / 2476-2296.1000175$

Page 5 of 8

Figure 4a shows excitation spectra of ITO nanoparticles prepared at different doping concentration of tin at $470 \mathrm{~nm}$ emissions. The characteristic peaks at $\sim 400$ and $410 \mathrm{~nm}$ are found. We want to see the quantum confinement effects with particle size. We choose the adsorption edge for band gap calculation. Absorption edges of samples for different dopant concentration of $\mathrm{Sn}$ are found to be almost same as $330 \pm 5 \mathrm{~nm}$. Here, the absorption edge is taken as a point where the minimum point at intensity (y-axis) occurs. There is no significance effect in lower dopant concentration of tin. We do not see any significant effect of particle size on the band gap. The band gap is found to be $\sim 330$ $\mathrm{nm}$. It is likely that surface effects are more predominant than that of particle size.

In further confirmation of ageing effect as well as effect of different emission wavelengths, the excitation measurement of ITO prepared at different doping concentration has been performed. Figure $4 \mathrm{~b}$ shows the excitation spectra of ITO prepared at different proportion, but the same sample is measured at $440,450,460,470 \mathrm{~nm}$ emission. At $470 \mathrm{~nm}$ emission, the absorption edge is found to be at $330 \mathrm{~nm}$, which is same as reported. However, there is slight blue shift as emission wavelength changes from 470 to $440 \mathrm{~nm}$. The point where the minimum point at intensity (y-axis) occurs is taken as absorption edge. This study confirms that quantum size can be observed only when the particle size is lower than the critical size. If the particle size is greater than the critical size, only surface effect is more predominant. The reported value of the critical size of ITO is $2.4 \mathrm{~nm}[11,12]$. In this study, the particle sizes are in the range 10 to $20 \mathrm{~nm}$. So, only surface effect will be more appropriate in order to understand property.
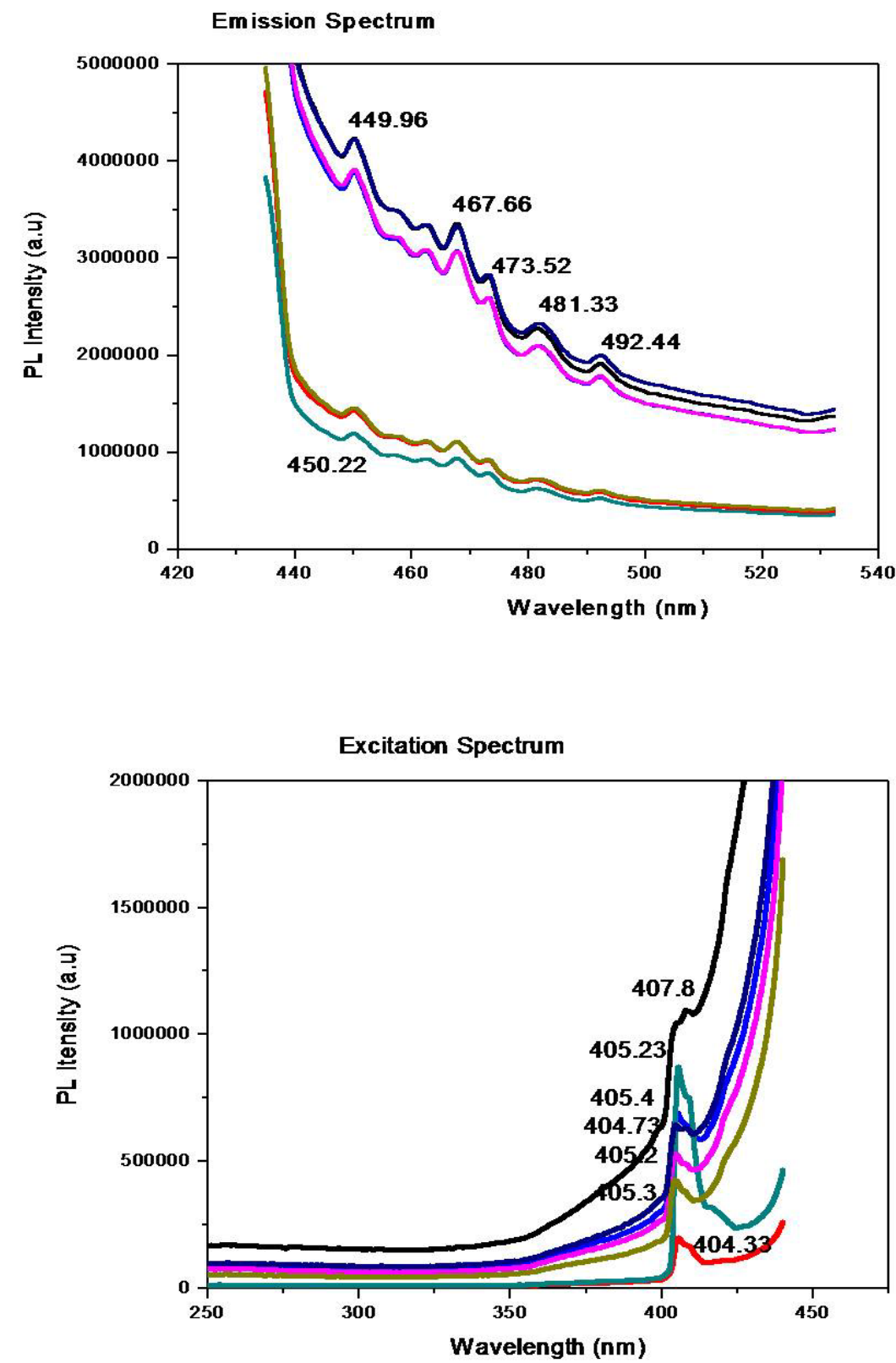

Figure 4: $(a$ and b) Emission Spectra and Excitation spectra of ITO (50:50, 70:30, 75:25, 80:20, 85:15, 90:10 and 95:05) NPs. 
Citation: Perumalsamy R, Prabhavathi G, Nivetha S, Mohamed Saleem A, Karunanithy M, et al. (2017) Study of Nanomaterials Prepared by Combustion Method Using High Heat Combustion Chamber and Agreement with the Reported Results. Fluid Mech Open Acc 4: 175. doi: 10.4172/2476-2296.1000175
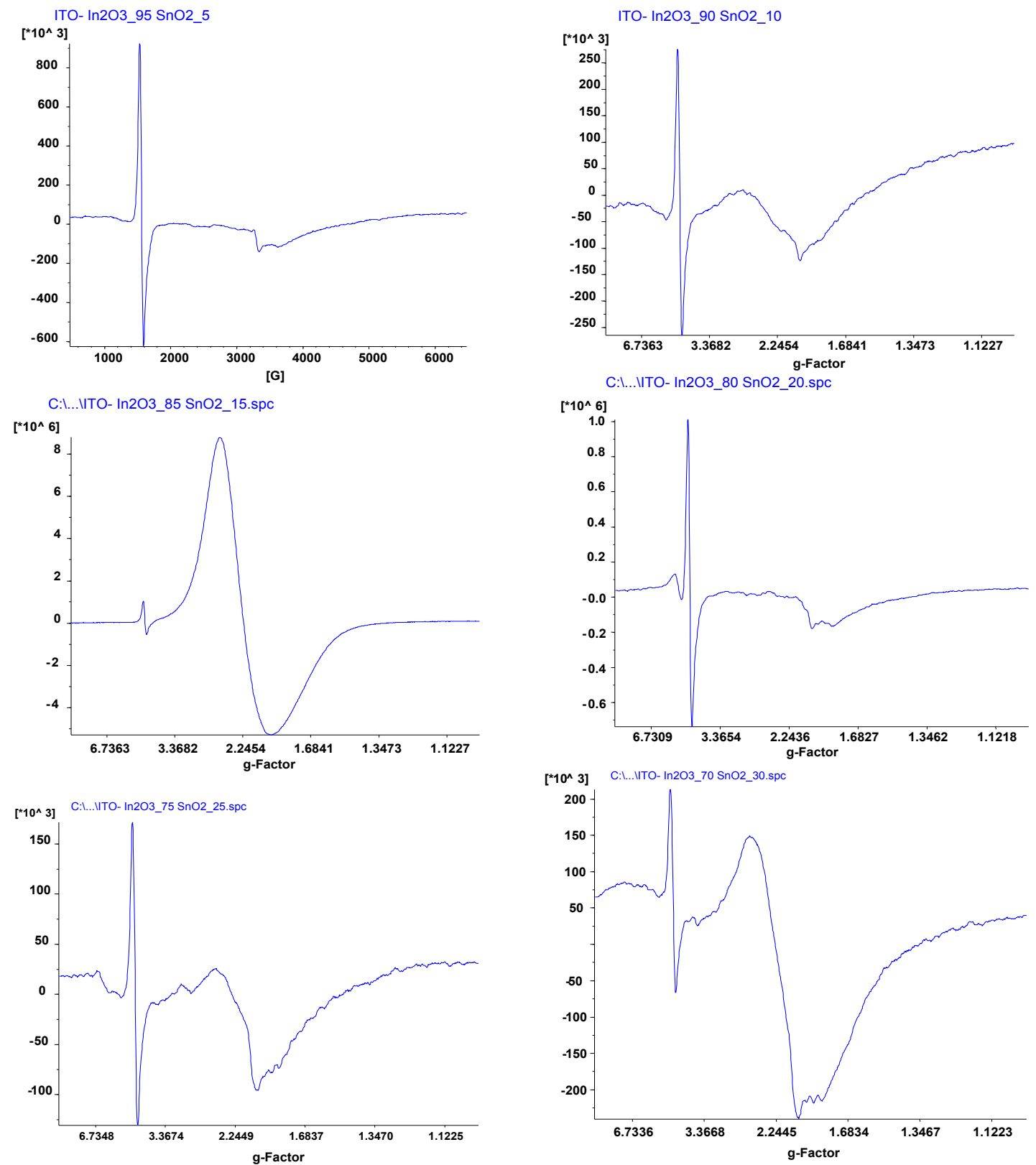

C:I...IITO-In2O3_50 SnO2_50.spc

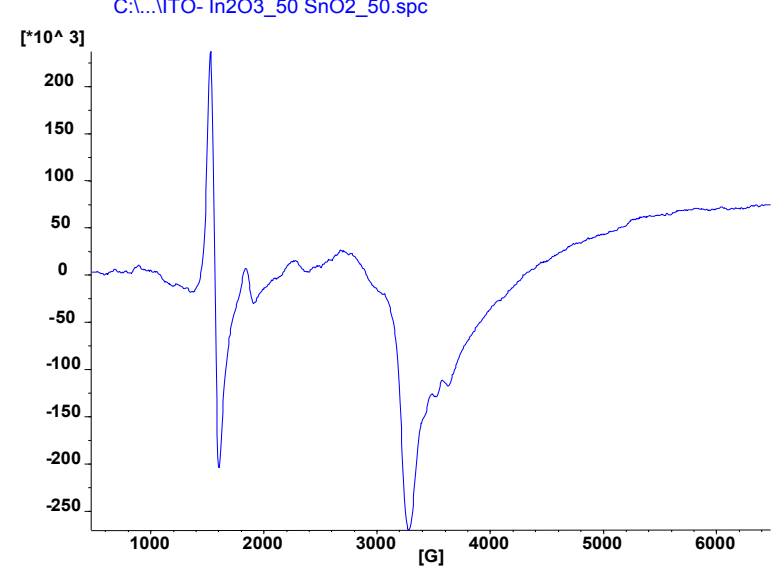

Figure 5: EPR studies of ITO (50:50, 70:30, 75:25, 80:20, 85:15, 90:10 and 95:05) NPs at different proportions. 
Citation: Perumalsamy R, Prabhavathi G, Nivetha S, Mohamed Saleem A, Karunanithy M, et al. (2017) Study of Nanomaterials Prepared by Combustion Method Using High Heat Combustion Chamber and Agreement with the Reported Results. Fluid Mech Open Acc 4: 175. doi: $10.4172 / 2476-2296.1000175$

Page 7 of 8

\begin{tabular}{|c|c|c|c|c|}
\hline Sample & Lattice const $\left(A^{0}\right)$ & Grain size $(\mathrm{nm})$ & $\mathbf{R}_{\text {Bragg }}$ & GOF \\
\hline $\mathrm{In}_{1.417} \mathrm{Sn}_{0.1156} \mathrm{O}_{2.36}$ & 10.139 & 12.4 & 1.118 & 1.15 \\
\hline $\mathrm{In}_{1.599} \mathrm{Sn}_{0.105} \mathrm{O}_{2.717}$ & 10.111 & 16.9 & 0.827 & 1.14 \\
\hline $\mathrm{In}_{1.68} \mathrm{Sn}_{0.119} \mathrm{O}_{2.772}$ & 10.115 & 17.8 & 1.048 & 1.18 \\
\hline $\mathrm{In}_{1.71} \mathrm{Sn}_{0.059} \mathrm{O}_{2.68}$ & 10.113 & 18.0 & 0.852 & 1.22 \\
\hline $\mathrm{In}_{1.775} \mathrm{Sn}_{0.081} \mathrm{O}_{2.82}$ & 10.119 & 18.6 & 1.139 & 1.15 \\
\hline $\mathrm{In}_{1.82} \mathrm{Sn}_{0.083} \mathrm{O}_{2.89}$ & 10.132 & 19.2 & 1.012 & 1.13 \\
\hline $\mathrm{In}_{1.94} \mathrm{Sn}_{0.0153} \mathrm{O}_{2.937}$ & 10.131 & 20.8 & 0.887 & 1.19 \\
\hline
\end{tabular}

Table 1: Structural values measure for the ITO at different proportions.

The atomic arrangement in the grain boundary seems to be somewhat different from regular periodic arrangement whereas inside the grain there is a good periodic arrangement of atoms.

Broad spectrum because of magnetic active substances contaminated when $\%$ of Indium increases electron density around decreases [13-15].

If $g$ factor experimental and calculated values are equal the $e^{-n}$ around the orbit are free $\mathrm{e}^{-\mathrm{ns}} \mathrm{spin}$, in orbital are explained in the figures. EPR studies showed the concentration dependence of monitoring the $\mathrm{In}^{3+}$ environment only lowers concentration of $\mathrm{Sn}^{2+}$ in ITO particle monitory the cation site by getting substituted in it. Above $0.5 \mathrm{~mol} \%$ Sn ions form correlated clusters, which lead to broadening. These EPR spectra were found to contain two different components, one from single isolated ions and the other from the clusters. Samples with 0.05 mol\% Sn ions dopant (lower content) showed sextet due to single ion, also sharp line at $\mathrm{g}=1.5$ electronic [16-18].

Acknowledgement Electron Paramagnetic resonance spectra were measured on a varian spectrometer with $100 \mathrm{kc} / \mathrm{s}$ field modulation and operating at about $9.2 \mathrm{Gc} / \mathrm{s}$. The signal enhancing runs were carried out using an analog digital converter, counting equipment and a 512 channel analysis (Webster and Jones, to be published). The sweep was triggered either by a sample of DPPH or by the strong control line $\left(\mathrm{m}_{1}=0\right)$ of the F centre [19]. The g values were measured using DPPH taking $g=2.0036$, in all spectra shown the magnetic field increases from left to right. The line-width quoted corresponds to the distance between the points of maximum slope of the absorption curve.

The analysis has been carried out for ITO crystallines samples with different proportion. The $\mathrm{g}$ factor of ITO.

$$
: g=1+\frac{S(S+1)+J(J+1)-l(l+1)}{2 J(J+1)}
$$

where $\mathrm{J}=\mathrm{l} \pm \mathrm{s}$ where $\mathrm{s}$ is spin orbital angular quantum number. When $\mathrm{L}=0 \mathrm{~S}=\mathrm{J} \mathrm{g}=2.000$. Atomic number of in is 49 electronic configuration is $[\mathrm{Kr}] 4 \mathrm{~d}^{10} 5 \mathrm{~s}^{2} 5 \mathrm{p}^{1}$

\section{$\mathrm{d}=7:+2:+1: 0:-1-2$ Total $\mathrm{L}=6-3=3$}

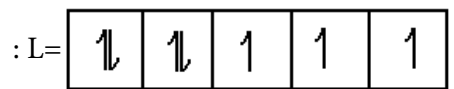

$42(-1)(-2)$

$:+2+10-14-2$

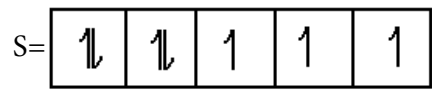

$: \frac{1}{2}+\frac{1}{2}+\frac{1}{2}=\frac{3}{2}$
$\mathrm{J}=\mathrm{L}+\mathrm{S}=3+\frac{3}{2}=\frac{9}{2}$ so $\mathrm{g}$ values $\frac{4}{3}=1.3333$ like that for tin atomic number 50 electronic configuration $[\mathrm{Kr}] 4 \mathrm{~d}^{10} 5 \mathrm{~s}^{2} 5 \mathrm{p}^{2} \mathrm{Sn}^{4+}, \mathrm{d}^{6}$

$:+2+10-1-2$

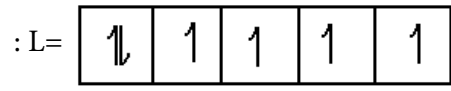

:4 $1-1-2=5-3=2$

$: S=\frac{1}{2}+\frac{1}{2}+\frac{1}{2}+\frac{1}{2}=2$

: $\mathrm{J}=\mathrm{L}+\mathrm{S}=2+2=4$ obtained $\mathrm{g}$ values are $\frac{3}{2}=1.5 \mathrm{ITO} \mathrm{g}>2.0000$.

In this Indium Tin oxide sample with a natural isotope abundance of 49In NO. $15 \%$ show a strong line at $\mathrm{g}=1.3333$ after neutron irradiation in vacuo, which is thought to originate from $\mathrm{F}$ centers in the bulk, together with same further lines just to the high-field side which arise form surface centers (Nelson and Frank [20]); on the addition of oxygen those additional lines disappear immediately leaving the F-center line which itself decays slowly (Tench and Nelson)[3]. The sample containing different $\mathrm{Sn}$ content showed a distinct hyperfine structure in addition to a strong line at $\mathrm{g}>2.000$ of line-width about $0.1 \mathrm{G}$; the lines were centered on $\mathrm{g}>2.000$ and the stronger lines have a measured hyperfine splitting of $8.3 \pm 0.1 \mathrm{G}$ corresponding to a hyperfine interaction with one nuclear of spin $(3 / 2+2)=7 / 2$ some low intensity lines are also present which probably arise from F-aggregate centers, these are also, observed in the normal ITO powders [21] Selected EPR studies were reported in the Figure 5 and Table 1.

\section{Conclusion}

ITO powders containing relatively high content of Sn were prepared by Combustion starting: with metal salts maintaining: different $\frac{I n}{S n}$ ratios 50:50, 70:30, 75:25, 80:20, 85:15, 90:10 and 95:05 EPR studies reflected a possible transformation of hydrated In(III) and $\mathrm{Sn}(\mathrm{IV})$ hydroxides to their oxides. It was found that in ITO, for smaller grain sizes up to $10-20 \mathrm{~nm}$. X-ray diffraction studies showed that the decomposition of In(III)-sn(IV) hydroxides in the mixed system(up to $50 \%$ of $\mathrm{Sn}$ to $5 \%$ of $\mathrm{Sn}$ ) prefers the path of pure In(III) hydroxide $\rightarrow$ $\mathrm{In}_{2} \mathrm{O}_{3}$ whereas above $50 \%$ of $\mathrm{Sn}$, the decomposition pattern prefers the path of $\mathrm{sn}(\mathrm{IV})$ hydroxide $\rightarrow \mathrm{SnO}_{2}$.

\section{References}

1. Bagheri-Mohagheghi MM, Shahtahmasebi N, Alinejad MR, Youssefi A Shokooh-Saremi M (2008) The effect of the post-annealing temperature on the nano-structure and energy band gap of $\mathrm{SnO}_{2}$ semiconducting oxide nanoparticles synthesized by polymerizing-complexing sol-gel method. Physica B: Condensed Matter 403: 2431-2437.

2. Bose AC, Kalpana D, Thangadurai P, Ramasamy S (2002) Synthesis and characterization of nanocrystalline $\mathrm{SnO}_{2}$ and fabrication of lithium cell using nano- $\mathrm{SnO}_{2}$. Journal of Power Sources 107(1): 138-141. 
Citation: Perumalsamy R, Prabhavathi G, Nivetha S, Mohamed Saleem A, Karunanithy M, et al. (2017) Study of Nanomaterials Prepared by Combustion Method Using High Heat Combustion Chamber and Agreement with the Reported Results. Fluid Mech Open Acc 4: 175. doi: 10.4172/2476-2296.1000175

Page 8 of 8

3. Tench AJ, Nelson RL (1967) Electron spin resonance of F centres in irradiated $43 \mathrm{CaO}$ and other alkaline earth oxides. Proceedings of the Physical Society 92: 1055.

4. Lee DH, Vuong KD, Condrate RA, Wang XW (1996) FTIR investigation of RF plasma deposited indium-tin oxide films on glasses. Materials Letters 28: 179-182.

5. Abel EW, Bailar HJ, Emeleus R, Nyholum A, Trotman T (1973) Comprehensive Inorgranic Chemistry. Pergamon, Neww York 1: 43-104.

6. Giesekke EW, Gutowsky HS, Kirkov P, Laitinen HA (1967) A proton magnetic resonance and electron diffraction study of the thermal decomposition of tin (IV) hydroxides. Inorganic Chemistry 6: 1297.

7. Schwartz J, Bruner EL, Koch N, Span AR, Bernasek SL, et al. (2003) Controlling the work function of indium tin oxide: differentiating dipolar from local surface effects. Synthetic metals 138: 223-227.

8. Bose AC, Balaya P, Thangadurai P, Ramasamy S (2003) Grain size effect on the universality of ac conductivity in $\mathrm{SnO}_{2}$. Journal of Physics and Chemistry of Solids 64: 659-663.

9. Purvis KL, Lu G, Schwartz J, Bernasek SL (2000) Surface characterization and modification of indium tin oxide in ultrahigh vacuum. Journal of the American Chemical Society 122: 1808-1809.

10. Bruner EL, Koch N, Span AR, Bernasek SL, Kahn A, et al. (2002) Controlling the work function of indium tin oxide: differentiating dipolar from local surface effects. Journal of the American Chemical Society 124: 3192-3193.

11. Kaviyarasu K, Ayeshamariam A, Manikandan E, Kennedy J, Ladchumananandasivam R, et al. (2016) Solution processing of CuSe quantum dots: Photocatalytic activity under RhB for UV and visible-light solar irradiation Materials Science and Engineering 210: 1-9.

12. Span AR, Bruner EL, Bernasek SL, Schwartz J (2001) Surface modification of indium tin oxide by phenoxytin complexes. Langmuir 17: 948-952.

13. Ayeshamariam A, Bououdina M, Sanjeeviraja C (2013) Optical, electrical and sensing properties of $\ln _{2} \mathrm{O}_{3}$ nanoparticles. Materials Science in Semiconductor Processing 16: 686-695.

14. Ramaiah KS, Raja VS, Bhatnagar AK, Tomlinson RD, Pilkington RD, et al (2000) Optical, structural and electrical properties of tin doped indium oxide thin films prepared by spray-pyrolysis technique. Semiconductor science and technology 15: 676 .

15. Pramanik NC, Biswas PK (2002) Development of nano indium tin oxide (ITO) grains by alkaline hydrolysis of In (III) and Sn (IV) salts. Bulletin of Materials Science 25: 505-507.

16. VanderKam SK, Gawalt ES, Schwartz J, Bocarsly AB (1999) Electrochemically active surface zirconium complexes on indium tin oxide. Langmuir 15: 65986600 .

17. Jeong J, Choi SP, Chang Cl, Shin DC, Park JS, et al. (2003) Photoluminescence properties of $\mathrm{SnO}_{2}$ thin films grown by thermal CVD. Solid State Communications 127: 595-597.

18. Ishii K, Hirose $\mathrm{Y}$, Fujitsuka $\mathrm{H}$, Ito O, Kobayashi N (2001) Time-resolved EPR, fluorescence, and transient absorption studies on phthalocyaninatosilicon covalently linked to one or two tempo radicals. Journal of the American Chemical Society 123: 702-708.

19. Stepanyan S, Hicks K, Carman DS, Pasyuk E, Schumacher RA (2003) Observation of an exotic $S=+1$ baryon in exclusive photoproduction from the deuteron. Physical Review Letters 91: 252001.

20. Nelson PG, Frank K (1967) Anomalous rectification in cat spinal motoneurons and effect of polarizing currents on excitatory postsynaptic potential. Journal of Neurophysiology 30: 1097-1113.

21. Marikkannu S, Kashif M, Sethupathy N, Vidhya VS, Piraman S (2014) Effect of substrate temperature on indium tin oxide (ITO) thin films deposited by jet nebulizer spray pyrolysis and solar cell application. Materials Science in Semiconductor Processing 27: 562-568. 